\title{
Modified impedance source inverter for power conditioning system
}

\author{
J SUGANTHI $^{1, *}$ and M RAJARAM ${ }^{2}$ \\ ${ }^{1}$ Department of Electrical and Electronics Engineering, Government College of Engineering, \\ Tirunelveli 627007, India \\ ${ }^{2}$ Anna University, Chennai 600025, India \\ e-mail: suganthi_shyam@rediffmail.com; suganthi@gcetly.ac.in; rajaramgct@rediffmail.com
}

MS received 28 April 2015; revised 4 March 2016; accepted 10 November 2016

\begin{abstract}
Based on classical impedance source inverter concept, this paper presents a modified impedance source inverter controlled by different pulse width modulation control strategies for solar PV/battery-powered applications. A brief topology analysis, generalized discussion and design of impedance network elements are presented. Comparison with the classical impedance source inverter is presented. Using simulation, analytical results are presented that ensure stability. The proposed voltage type inverter has reduced inrush current at startup, less capacitor voltage stress and minimum inductor current ripples. DC link voltage boost, reduced total harmonic distortion of output current and voltage, better voltage gain and wide range of output voltage control can be achieved easily with improved power quality. Experimental set-up of the modified impedance source inverter with Field Programmable Gate Array (FPGA) controller has been constructed to ascertain the results.
\end{abstract}

Keywords. Modified impedance source inverter; power conditioning system; cross conduction period; modified space vector pulse width modulation; field programmable gate array.

\section{Introduction}

The recently developed impedance source inverter (ZSI) topologies are a better choice of replacement for traditional voltage source inverters used in almost all renewable energy systems. The conventional power conditioning system (PCS) requires two stages of power conversion, which reduces efficiency [1]. Moreover, conventional voltage source inverters cannot withstand cross conduction or shoot through of switches in the same phase leg. To avoid cross conduction, a dead band interval must be provided. But the single-stage ZSIs can withstand cross conduction and have ride-through capability during frequent voltage variations encountered in renewable energy systems [2]. In the classical ZSI, a lattice network comprising two inductors and two capacitors is connected between the DC source and inverter main circuit as shown in figure 1. The ZSI effectively utilizes the cross conduction period and boosts the available dc link voltage. The classical ZSI concept, operating principle, advantages [3-5] and different pulse width modulation (PWM) control strategies used to control the shoot-through duty ratio were presented $[6,7]$.

This paper concentrates on a modified ZSI as proposed and examined in [8] for solar PV systems. Compared with classical ZSI topology the positions of the coupled impedance lattice network and diode were changed without any additional components as illustrated in figure 2 with different colour.

\section{Generalized topological analysis}

All the power switches and diodes used in the modified ZSI are exactly the same as those of the classical ZSI. However, the connection directions of capacitors and arrangement of diode and three-phase inverter are reversed as illustrated in figure 2. This topological modification leads to reduction of voltage stress across the capacitors, avoids inrush current at startup with the same boost capability as that of classicalZSI. All the PWM control strategies of classical ZSI can be implemented on the modified ZSI for solar PV/batteryfed systems.

\subsection{Drawbacks of classical ZSI}

- Voltage across the capacitors used in impedance network is always greater than the input DC voltage. Hence high-voltage capacitors are necessary in the case of ZSI.

- At startup, voltage and current surge occurs due to the high inrush current and resonance by Z-network Inductors and Capacitors. The classical ZSI cannot

*For correspondence 


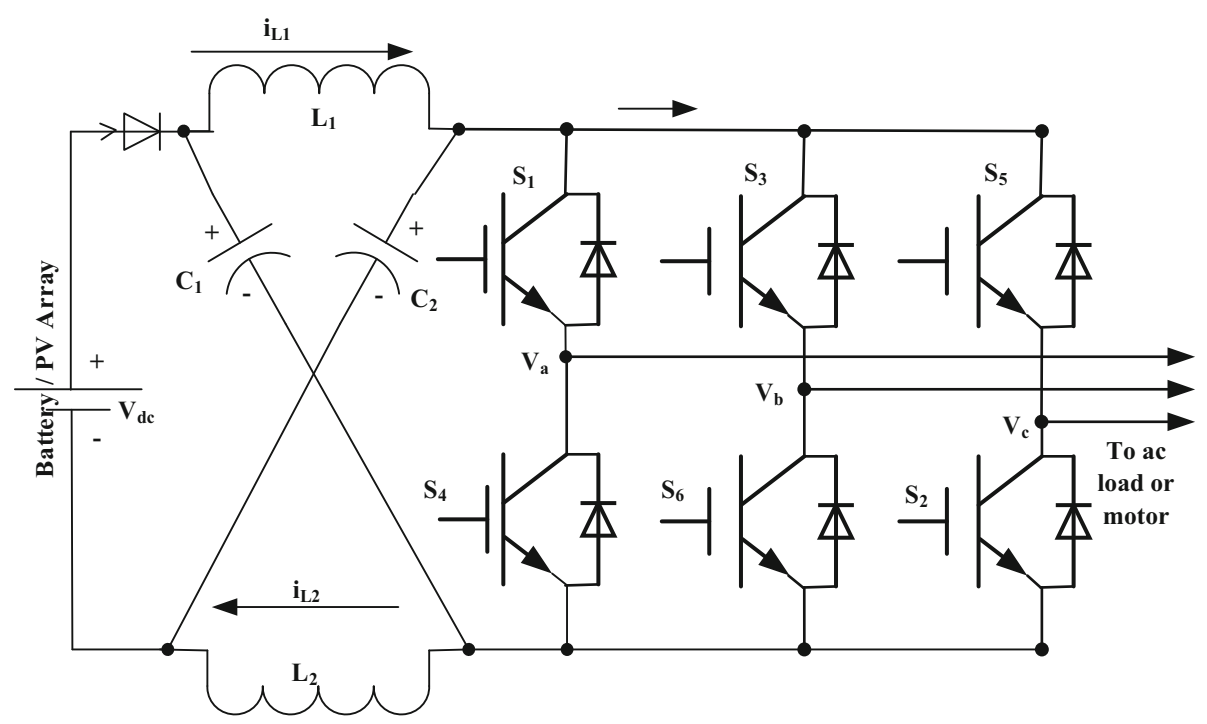

Figure 1. Classical impedance source inverter.

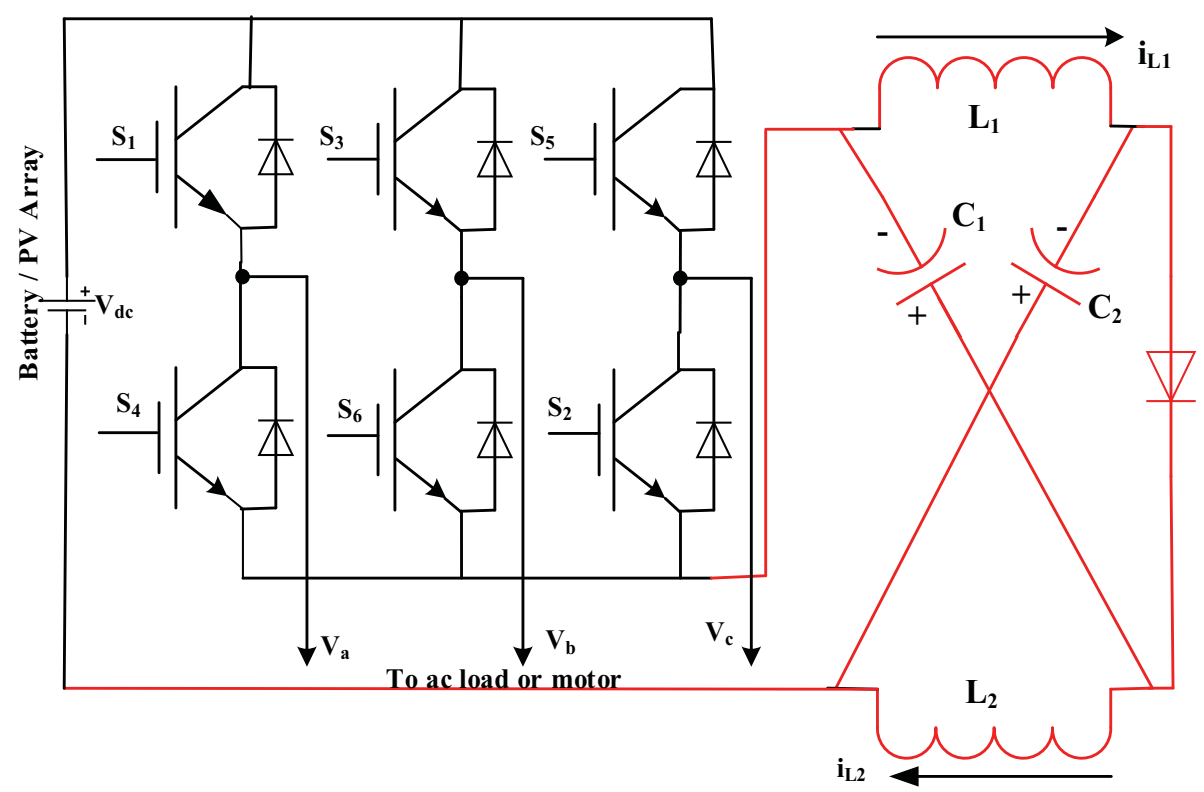

Figure 2. Modified impedance source inverter.

suppress them. Hence it is impossible to achieve softstart capability $[8,9]$.

In order to overcome the aforementioned drawbacks of classical ZSI, the way in which the impedance network connected is modified to develop a new topology known as modified ZSI as explained and tested in $[8,9]$.

' $M$ ' is the modulation index. From table 1, all the parameters except capacitor voltage of both the topologies remain the same. When cross conduction or shoot-through duty ratio $\left(D_{s h}\right)$ is zero the impedance network capacitor voltage is also zero in the case of modified ZSI. However, in classical ZSI the impedance network capacitor voltage is equal to the input DC voltage $V_{d c}$ for zero cross conduction interval. Hence it is possible to vary $D_{s h}$ from 0 to 0.5 gradually to achieve soft-start strategy and reduce voltage stress across capacitors in modified ZSI topology.

Moreover, by adopting soft-start control the possibility of resonance in impedance network of modified ZSI can be eliminated. Compared with the classical ZSI, the capacitor voltage stress at impedance network is greatly reduced in the case of modified ZSI for the same boost ability as presented and compared in table 1. 
Table 1. Comparison of classical ZSI and proposed topology.

\begin{tabular}{lcc}
\hline Parameters & Classical ZSI & Modified ZSI \\
\hline Boost factor, $B$ & $\frac{1}{1-2 D_{s h}}$ & $\frac{1}{1-2 D_{s h}}$ \\
Capacitor voltage, $V_{C}$ & $\frac{1-D_{s h}}{1-2 D_{s h}} V_{d c}$ & $\frac{D_{s h}}{1-2 D_{s h}} V_{d c}$ \\
DC link voltage, $V_{P N}$ & $\frac{1}{1-2 D_{s h}} V_{d c}$ & $\frac{1}{1-2 D_{s h}} V_{d c}$ \\
Peak output voltage per phase, $V_{P}$ & $M B \frac{V_{d c}}{2}$ & $M B \frac{V_{d c}}{2}$ \\
\hline
\end{tabular}

\section{Pulse width modulation (PWM) control strategies}

Table 2 lists the parameters that depend on the type of control strategy used.

\subsection{Simple boost control (SBC)}

SBC is a very simple constant shoot-through state control that uses five reference waveforms. As illustrated in figure 3 , there are three modulating waveforms and two constant straight lines greater than or equal to the modulating signal $[10,11]$. When the carrier triangular waveform is greater than the upper constant reference line or lower than the bottom reference line the circuit turns into shootthrough or cross conduction state. Otherwise the ZSI operates as like a conventional carrier-based PWM. In this method of control, obtainable cross conduction period varies with modulation index. The vertical thin lines represent shoot-through time period as shown in figure 3 .

\subsection{Maximum constant boost control (MCBC)}

This method is suitable to achieve maximum voltage gain with reduced voltage stress across the switches than through SBC, while always keeping the shoot-through duty ratio constant. As illustrated in figure 4, there are five modulating curves such as three modulating reference waveforms, upper shoot-through envelope and lower shootthrough envelope as derived and validated in [12]. Both envelope curves are periodical and their frequency is three times the output frequency. The distance between the envelopes is always constant, i.e., $\sqrt{3} \mathrm{M}$. Hence $D_{s h}$ is always constant.

\subsection{Maximum constant boost control with third harmonic injection (MCBCTHI)}

A third harmonic component with $16.67 \%$ or $1 / 6$ th of the fundamental component is injected into the three-phase voltage references as illustrated in figure 5. A unique feature can be obtained by considering two straight lines to control the shoot-through time or cross conduction period with 1/6th of third harmonic injection as explained and validated in [12]. The ideal voltage stress is considered as 1. Maximum constant boost control methods are highly attractive and can be used for applications requiring voltage gain of two or three.

\subsection{Modified space vector pulse width modulation (MSVPWM)}

Space Vector Pulse Width Modulation techniques are widely used in industrial applications and drive systems of PWM inverters because of their reduced current harmonics and increased modulation index. The optimized SVPWM technique is suitable for controlling shoot-through states of ZSI topologies [13]. Table 3 lists the 15 possible switching states of a three-phase-voltage-type modified ZSI. There are seven forbidden shoot-through states that short circuit any one phase leg (states ST1-ST3), any two phase legs (states ST4-ST6) or all three phase legs (state ST7). States ST1-ST7 are used to control the DC link capacitor voltage and can diminish the null states partially within a fixed switching cycle. This can be achieved by short circuiting the three-phase-voltage-type inverter phase legs, thus producing zero voltage across the connected AC load.

As an illustration, figure 6 illustrates the Modified Space Vector Pulse Width Modulation by inserting the forbidden shoot-through states in the existing SVPWM state patterns of a traditional VSI for controlling a three-phase modified ZSI topology. In the conventional SVPWM technique, normally six state transitions in one carrier period $T_{s}$ are possible. Preferably, six equal shoot-through or cross

Table 2. Comparison of different PWM control methods.

\begin{tabular}{lccc}
\hline Control method & Simple boost control & Maximum constant boost control & MSVPWM control \\
\hline Shoot-through duty ratio, $D_{s h}$ & $1-M$ & $\frac{2-\sqrt{ } 3 M}{2}$ & $\frac{2 \pi-3 \sqrt{ } 3 M}{2 \pi}$ \\
Boost factor, $B$ & $\frac{1}{2 M-1}$ & $\frac{1}{\sqrt{3} M-1}$ & $\frac{\pi}{\sqrt{ } 3 M-\pi}$ \\
Voltage gain, $G$ & $\frac{M}{2 M-1}$ & $\frac{G}{\sqrt{3} M-1}$ & $\frac{\pi M}{3 \sqrt{ } 3 M-\pi}$ \\
Max. modulation index, $M_{\max }$ & $\frac{G}{2 G-1}$ & $(\sqrt{ } 3 G-1) V_{d c}$ & $\frac{\pi}{3 \sqrt{3} G-\pi}$ \\
Voltage stress, $V_{s}$ & $(2 G-1) V_{d c}$ & $\frac{3 \sqrt{ } 3 G-\pi}{\pi} V_{d c}$ \\
\hline
\end{tabular}




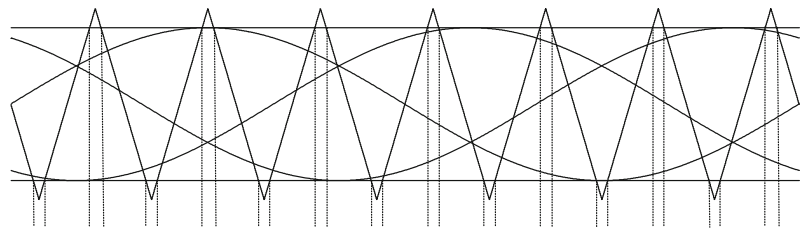

Figure 3. Reference waveforms for SBC.

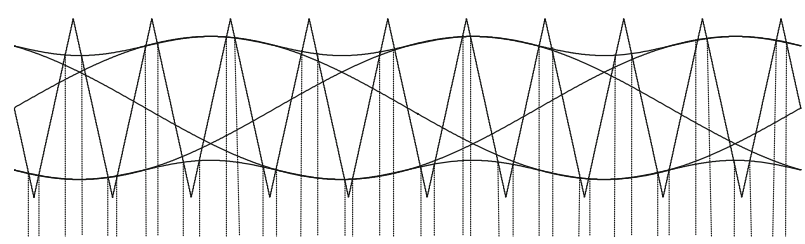

Figure 4. Reference waveforms for MCBC.

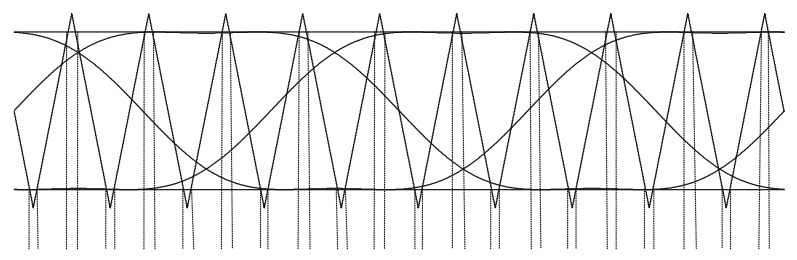

Figure 5. Reference waveforms for MCBCTHI.

conduction periods are inserted at every state transit, null states are diminished partially and equal interval null states are maintained at the start and end of the switching cycle $T_{s}$. Hence the same harmonic performance can be realized. By keeping the active state time period constant, cross conduction periods are inserted immediately to the left of first state transit and to the right of second state transit and so on $[14,15]$.

This way of inserting shoot-through states ensures only one device switching at all state transitions and allows the application of only three forbidden shoot-through states such as ST1-ST3 [16-18]. The other shoot-through or cross conduction periods cannot be used since they require the switching of two phase legs or more phase legs at every switching transition. In this way, correct insertion of shootthrough states during rising and falling carrier edge leads to better harmonic profile and minimum current ripple across the inductors connected in impedance network. Hence the size of the inductors in Z-network can be reduced [19].

$T_{s}=$ time period for one switching cycle.

$T_{s h}=$ shoot-through time period.

$T_{1}, T_{2}=$ time interval for active states.

$T_{0}=$ time interval for null states.

The MSVPWM control strategy provides greater flexibility to optimize the switching waveforms.

\section{Maximum power point tracking (MPPT)}

The single-stage modified ZSI inherits all the advantages of ZSI topology. The forbidden shoot-through state can be controlled easily with different PWM control strategies and effectively used in a power conditioning system with solar PV module as input voltage source. The output voltage of solar PV depends on light intensity and temperature. Moreover, the output current of solar PV module varies with irradiation. Hence fluctuations in output voltage of solar PV module will be high and unavoidable. By properly controlling the shoot-through duty ratio, the DC link

Table 3. Switching states of three-phase modified ZSI topology (! $S_{1}, ! S_{3}$ and $! S_{5}$ represent complement of $S_{1}, S_{3}$ and $S_{5}$, respectively).

\begin{tabular}{|c|c|c|c|c|c|c|c|}
\hline State & Output voltage & $\mathrm{S}_{1}$ & $\mathrm{~S}_{4}$ & $\mathrm{~S}_{3}$ & $\mathrm{~S}_{6}$ & $\mathrm{~S}_{5}$ & $\mathrm{~S}_{2}$ \\
\hline ACTIVE [100] & Finite & 1 & 0 & 0 & 1 & 0 & 1 \\
\hline ACTIVE [110] & Finite & 1 & 0 & 1 & 0 & 0 & 1 \\
\hline ACTIVE [010] & Finite & 0 & 1 & 1 & 0 & 0 & 1 \\
\hline ACTIVE [011] & Finite & 0 & 1 & 1 & 0 & 1 & 0 \\
\hline ACTIVE [001] & Finite & 0 & 1 & 0 & 1 & 1 & 0 \\
\hline ACTIVE [101] & Finite & 1 & 0 & 0 & 1 & 1 & 0 \\
\hline NULL [000] & $0 \mathrm{~V}$ & 0 & 1 & 0 & 1 & 0 & 1 \\
\hline NULL [111] & $0 \mathrm{~V}$ & 1 & 0 & 1 & 0 & 1 & 0 \\
\hline Shoot through [ST1] & $0 \mathrm{~V}$ & 1 & 1 & $\mathrm{~S}_{3}$ & $! \mathrm{S}_{3}$ & $\mathrm{~S}_{5}$ & $! S_{5}$ \\
\hline Shoot through [ST2] & $0 \mathrm{~V}$ & $\mathrm{~S}_{1}$ & $! S_{1}$ & 1 & 1 & $\mathrm{~S}_{5}$ & $! \mathrm{S}_{5}$ \\
\hline Shoot through [ST3] & $0 \mathrm{~V}$ & $\mathrm{~S}_{1}$ & $! S_{1}$ & $\mathrm{~S}_{3}$ & $! S_{3}$ & 1 & 1 \\
\hline Shoot through [ST4] & $0 \mathrm{~V}$ & 1 & 1 & 1 & 1 & $\mathrm{~S}_{5}$ & $! S_{5}$ \\
\hline Shoot through [ST5] & $0 \mathrm{~V}$ & 1 & 1 & $\mathrm{~S}_{3}$ & $! S_{3}$ & 1 & 1 \\
\hline Shoot through [ST6] & $0 \mathrm{~V}$ & $\mathrm{~S}_{1}$ & $! S_{1}$ & 1 & 1 & 1 & 1 \\
\hline Shoot through [ST7] & $0 \mathrm{~V}$ & 1 & 1 & 1 & 1 & 1 & 1 \\
\hline
\end{tabular}




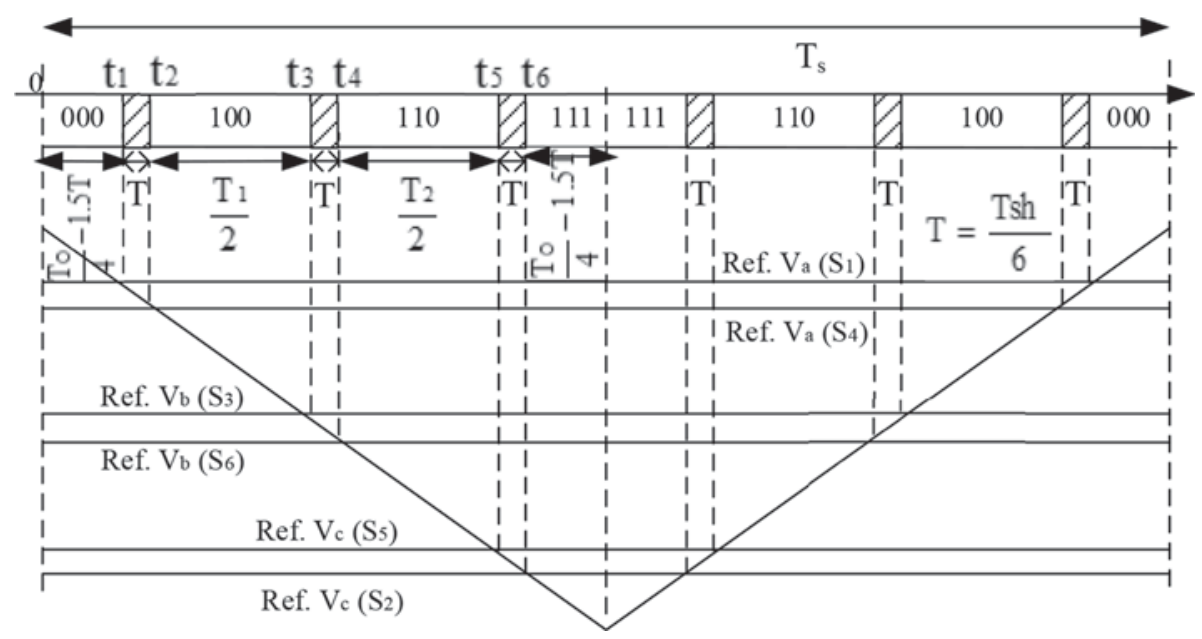

Figure 6. Sketch map of MSVPWM.

voltage can be boosted to any value during wide input voltage variations.

The maximum power output of solar PV module can be tracked effectively at any given temperature and irradiation. In this paper, to track maximum power the Perturbation and Observation method $(\mathrm{P} \& \mathrm{O})$ is used. This method is commonly used and the solar PV modules' voltage can be regulated at an optimal point to satisfy the relationship $\frac{d P}{d V}=0$. ' $P$ ' and ' $V$ ' are the power and voltage of solar PV module. Hence the maximum power point can always be tracked easily. This single-stage power conditioning system can realize the boost and inversion with maximum power tracking effectively.

In P\&O method the PI controller adjusts the voltage slightly from the array and measures power. If the power increases, further adjustments are tried in the same direction until no power increases as explained and verified in [20]. This method is commonly referred to as a hill climbing method, because it depends on the rising of the curvature of power against voltage below the maximum power point, and the fall above that point as illustrated in figure 7. This easy method results in high efficiency, provided by adopting the proper hill climbing strategy.

Therefore, the MPPT in a grid/AC-load-connected PV system will always attempt to operate the solar PV module at its maximum power point. Normally, solar PV modules work better in cold weather and MPPT is effectively and efficiently utilized to track the maximum power available from them.

\section{Design of impedance network}

Designing impedance network of modified ZSI is not the main scope of this paper. But based on the analysis and verification done in [21], the impedance network $L_{1}, L_{2}$ and
$\mathrm{C}_{1}, \mathrm{C}_{2}$ were designed. The inductors and capacitors at input side can act as filtering and storing elements, which improves the power quality at AC side. Generally we require inductors either in the input side or in the output side to improve the power factor. These inductors at input side can limit the current ripple through the devices during shoot-through state. Capacitors at input side can absorb the current ripple and maintain almost constant voltage to keep the output voltage sinusoidal. To avoid undesirable operating modes called as pseudo-active states, the impedance network elements should satisfy the following conditions as derived, explained and verified in [22].

$$
C \geq \frac{D_{s h} I_{l}}{2 f_{s} \Delta V_{c}} \text { and } L \geq \frac{D_{s h} I_{c}}{2 f_{s} \Delta I_{l}}
$$

where $I_{l}$ is average inductor current, $\Delta V_{c}$ is capacitor voltage ripple at peak power (5\% is chosen), $\Delta I_{l}$ is inductor current ripple at peak power (5\% is chosen) and $f_{s}$ is switching frequency.

\section{Simulation results, discussion and analysis}

The Modified ZSI with different control strategies has been simulated and simulation waveforms are illustrated in figures 8-11. The input DC voltage from PV array $\left(V_{P V}\right)=86 \mathrm{~V}$; impedance network elements $L_{1}=L_{2}=1$ $\mathrm{mH}$ and $C_{1}=C_{2}=2 \mathrm{mF} ; \mathrm{AC}$ Load of $R=6 \Omega$ and $L=2 \mathrm{mH}$; IGBTs are used as power switches in inverters. Switching frequency $\left(f_{s}\right)=10 \mathrm{kHz}$; the above parameters are common for all control strategies considered for comparison. The SBC, MCBC, MCBCTHI and MSVPWM control techniques are applied to modified ZSI. The voltage transfer ratio of modified ZSI with aforementioned control techniques is well above $100 \%$ with RL load as illustrated in table 4 and figures $8 \mathrm{c}-11 \mathrm{c}$. The simulation results of 


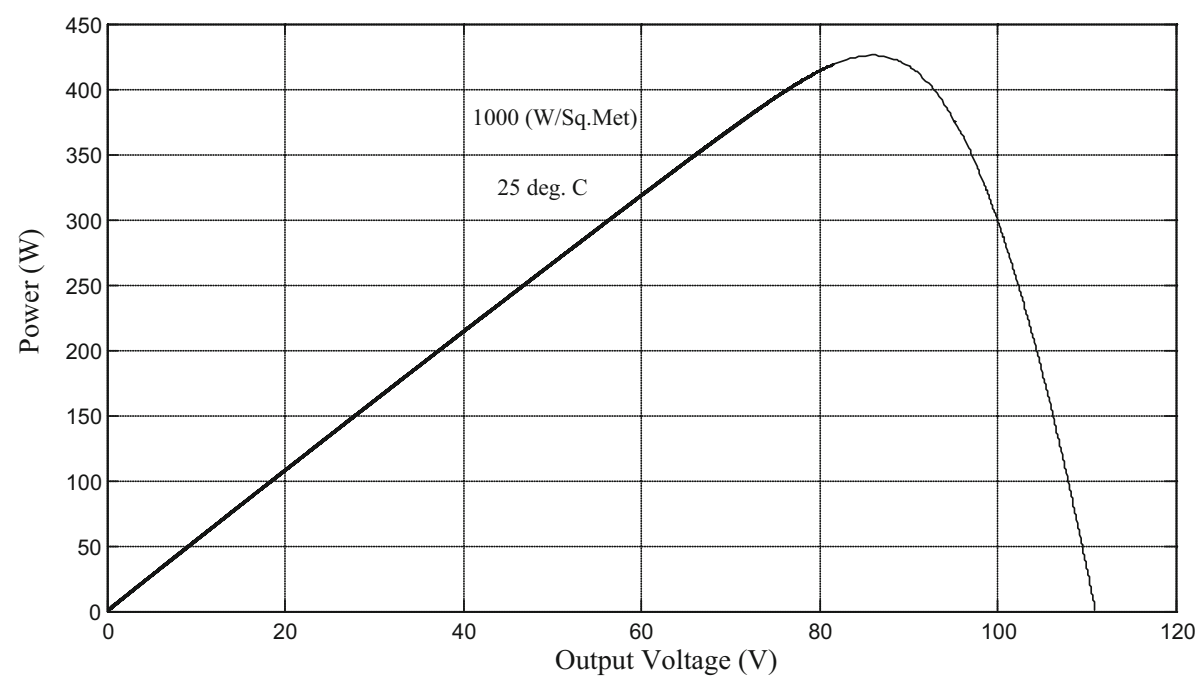

Figure 7. $P-V$ characteristics.

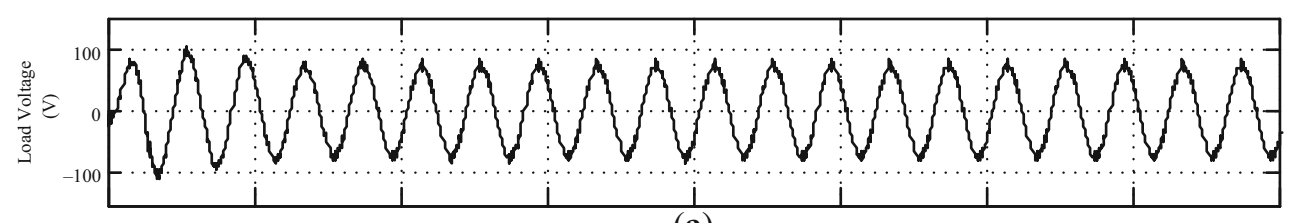

(a)

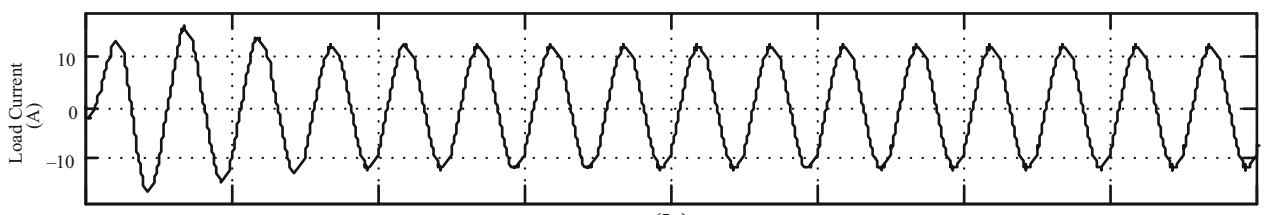

(b)

Time (s)

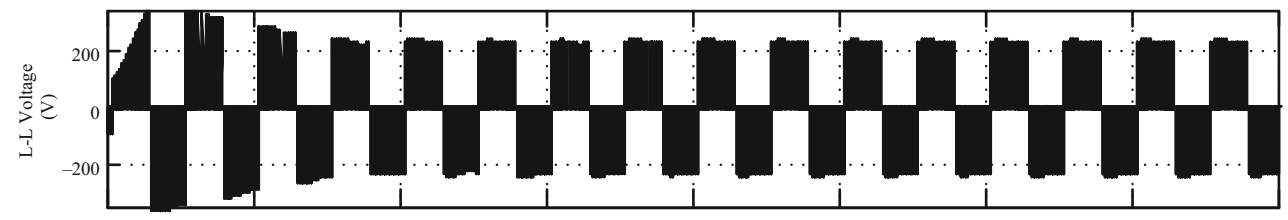

(c)

Time (s)

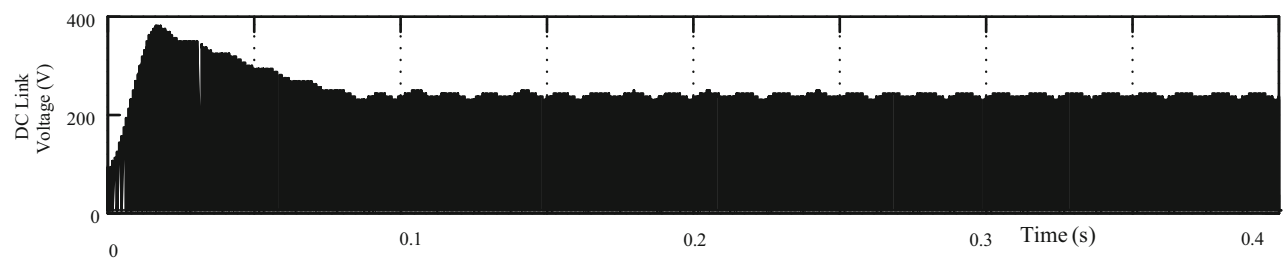

(d)

Figure 8. Simple boost control.

SBC, MCBC, MCBCTHI and the effective MSVPWM techniques are illustrated in figures $8 \mathrm{a}-\mathrm{d}, 9 \mathrm{a}-\mathrm{d}, 10 \mathrm{a}-\mathrm{d}$ and $11 \mathrm{a}-\mathrm{d}$, respectively.

In SBC control technique, voltage stress across the switches is reasonably high at high voltage gain. To obtain high voltage gain, modulation index must be small. Hence voltage stress $\left(V_{s}\right)$ is more. This is the major drawback of SBC technique [23].

In MCBC technique the voltage stress is less than that of SBC technique. This can be achieved by maintaining 


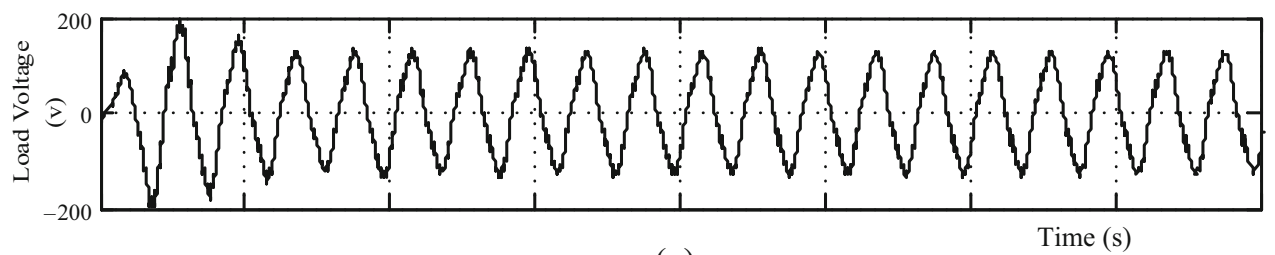

(a)

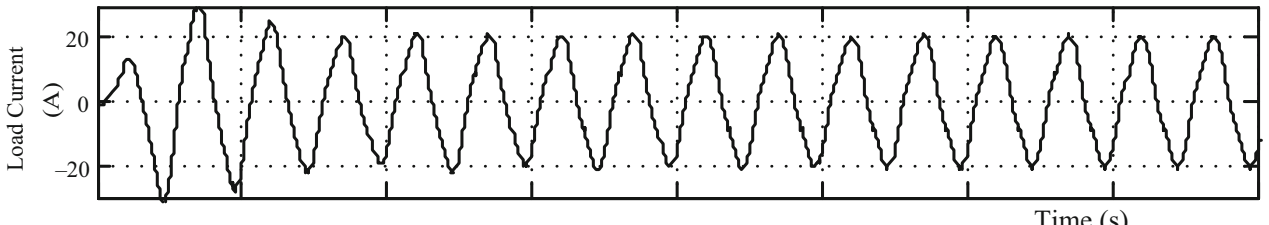

(b)

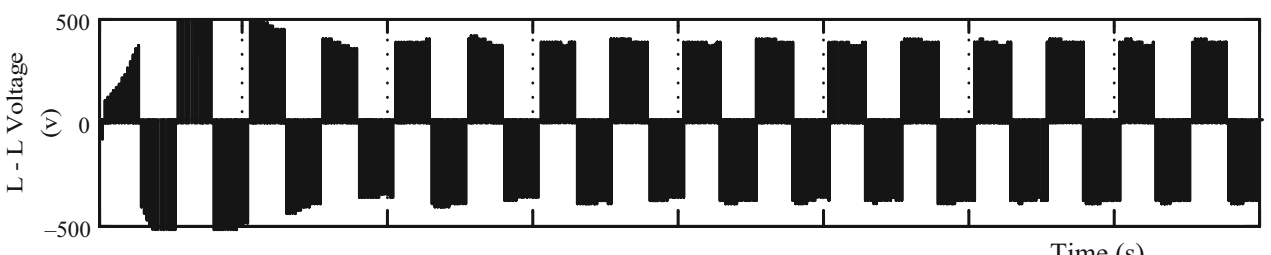

(c)

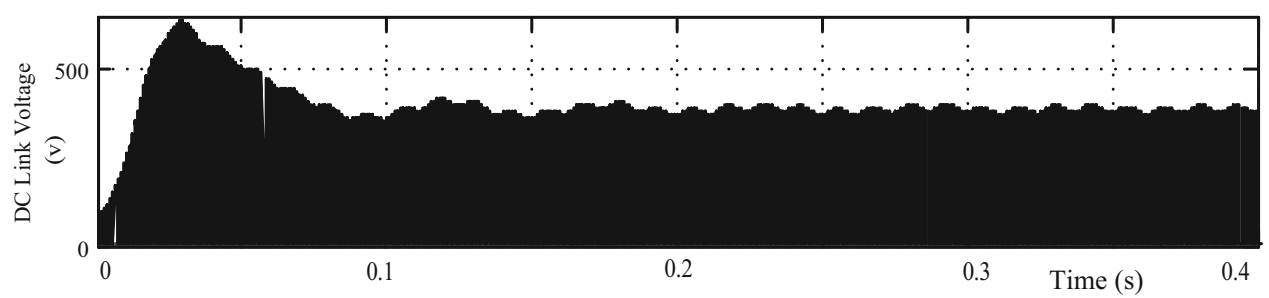

(d)

Figure 9. Maximum constant boost control.

constant shoot-through duty ratio. This method reduces the low frequency ripple components present in inductor current and capacitor voltage [24].

In MCBCTHI technique, $16.67 \%$ of third harmonic is injected; hence modulation index can be increased beyond one. Thereby smooth voltage gain can be obtained by varying the modulation index with shoot-through duty ratio. As illustrated in table 4, MCBCTHI method has reduced total harmonic distortion (THD) and low frequency ripples. Hence it minimizes the value of passive components required [25].

In MSVPWM method, the voltage stress is greatly reduced than in the other control methods because only one phase leg is allowed to shoot through at a time and THD of output is less than in the other control methods. However, in high power range applications, placing six shoot-through states in one switching cycle produces more losses than in other control methods as SBC and MCBC methods maintain constant shoot-through duty ratio. For low-power applications, MSVPWM is superior to other PWM control methods. Moreover, frequency of inductor current is six times more than that of output current frequency. The current ripple across impedance network inductors is minimum compared with other control strategies as illustrated in figure 12. Among the four control strategies considered, Modified Space Vector Pulse Width Modulation technique (MSVPWM) has many features like less voltage stress across the switches, less inductor current ripple and good current harmonic profile than in other control strategies and is suitable for adjustable speed AC drives [26].

As illustrated clearly in figure 12, the inductor current ripples in MSVPWM technique are much less than in the other control techniques considered for comparison. Hence it reduces the size of inductors required for impedance network [27]. During the shoot-through state, the inductor current rises and decreases during non-shoot-through state. Hence careful introduction of shoot-through period in each phase leg influences the inductor current and reduces the inductor current ripples. Thus, reduction in the size of inductors required for $Z$-network can be achieved. 


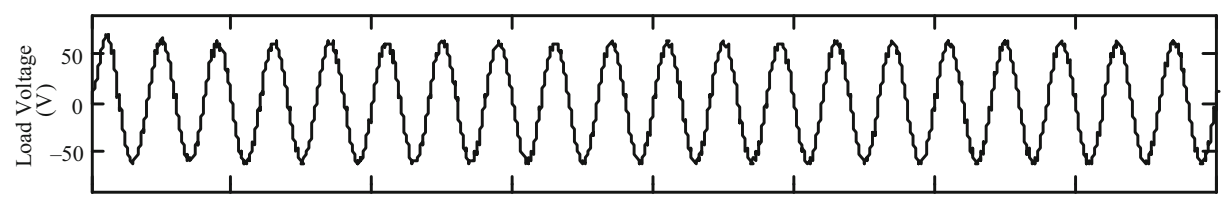

(a)

Time (s)

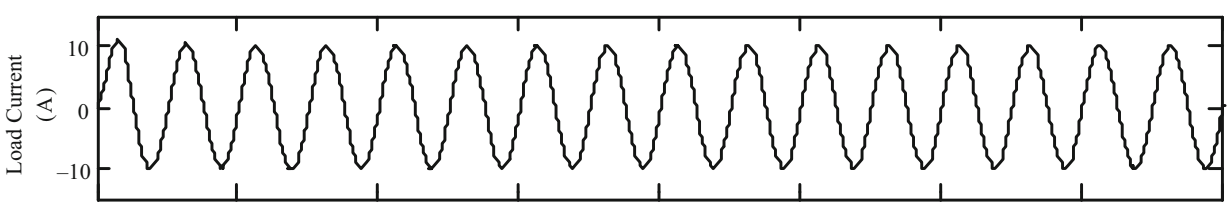

(b)

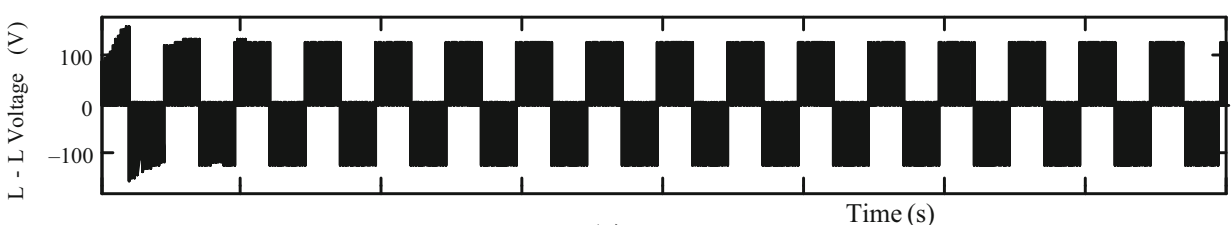

(c)

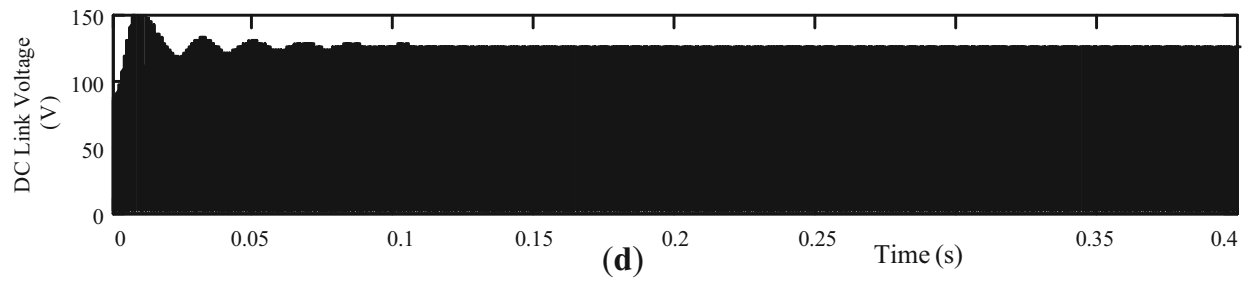

Figure 10. MCBC with third harmonic injection.

The input DC voltage is varied between 150 and $200 \mathrm{~V}$ at $0.5,1$ and $1.5 \mathrm{~s}$ as shown in figure 13. The capacitor voltage and DC link boost voltage will also vary with input voltage as shown in the second row of table 1 . By varying the shoot-through duty ratio, the capacitor voltage can be kept constant and then the DC link voltage will also be a constant value. This can be achieved with the help of PI controllers [28]. Another easy method is to control the DC link boost voltage at constant value and let the capacitor voltage vary [29].

The load current can be varied at 0.2 and $0.5 \mathrm{~s}$ as illustrated in figure 14. The inverter output voltage is maintained constant by varying the shoot-through duty ratio. Hence, the load voltage is maintained at constant value. The change in load from $500 \mathrm{~W}$ to $4 \mathrm{~kW}$ does not affect the load voltage with improved power quality.

\section{Experimental verification}

Experimental set-up of modified ZSI has been designed suitably and constructed for testing. The laboratory prototype set-up is illustrated in figure 15 for $60 \mathrm{~W}$ batterypowered applications. Three-phase RL load of $100 \mathrm{k} \Omega$, $30 \mathrm{mH}$ was chosen for testing. The input DC voltage of $64 \mathrm{~V}$ is supplied from a battery. The Z-network inductors of rating $1.5 \mathrm{mH}, 0.3 \mathrm{~A}$ and capacitors of rating $350 \mu \mathrm{F}$, $450 \mathrm{~V}$ are used in the set-up. IGBTs of rating $1200 \mathrm{~V}, 15 \mathrm{~A}$ are used as power switches in the three-phase-voltage-type modified ZSI.

\subsection{FPGA controller}

To generate the six gate pulses for the modified ZSI and to control shoot-through states using MSVPWM control strategy, a Xilinx Spartan 3E FPGA processor has been programmed and used with driver circuits. It provides many features in embedded processing and has over 10,000 logic cells. Spartan 3E programmability permits design upgrades easily. The three-phase inverter output voltage per phase is shown in figure 16, which can meet the load requirements. The harmonic spectrum of three-phase-voltage-type modified ZSI has been presented with a Yokogawa power harmonic analyzer as illustrated in figures 17 and 18. The system is designed in open loop mode and there are no feedback or feed-forward controllers.

Figure 17 presents the individual harmonic components of output voltage and figure 18 illustrates the THD spectrum of output voltage. Extensive simulation with solar PV array as input and MPPT is also carriedout simultaneously. To validate this concept, an experimental setup with battery 


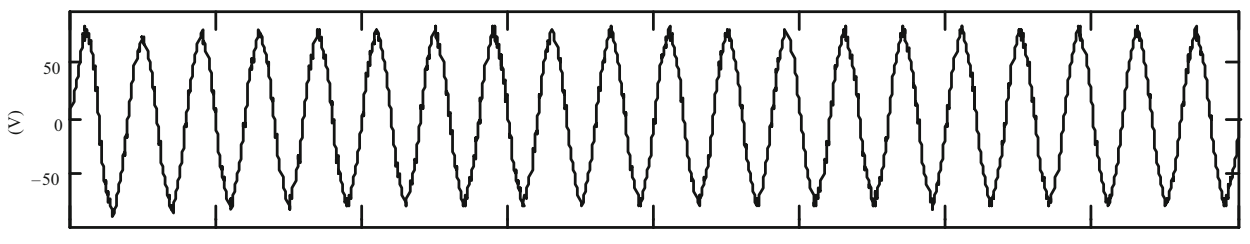

(a)

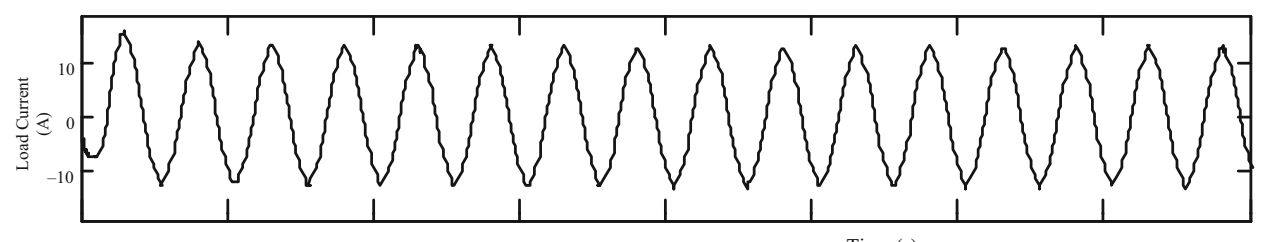

(b)

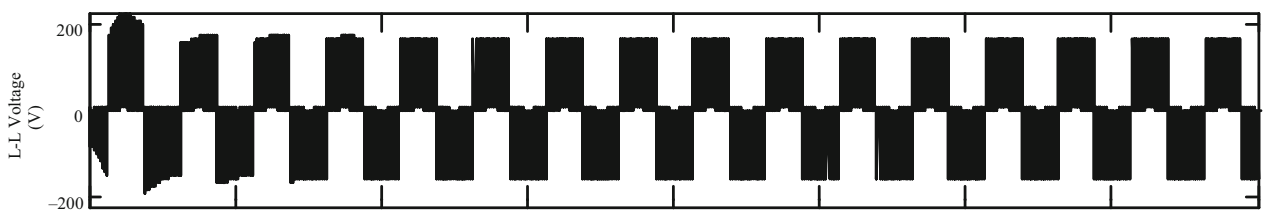

(c)

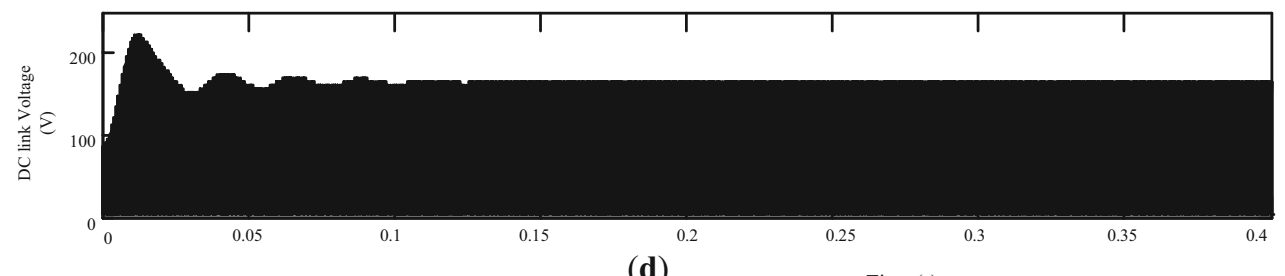

Figure 11. MSVPWM method.

Table 4. FFT analysis and voltage transfer ratio comparison.

\begin{tabular}{lccccc}
\hline & & \multicolumn{2}{c}{ Load voltage \% THD } & & \multicolumn{2}{c}{ Load current \% THD } \\
\cline { 3 - 4 } Control method & Obtained voltage transfer ratio $(\%)$ & $D_{s h}=0.2$ & $D_{s h}=0.2851$ & $D_{s h}=0.2$ & $D_{s h}=0.2851$ \\
\hline SBC & 171.98 & 4.33 & 5.56 & 1.88 & 2.09 \\
MCBC & 276.395 & 8.42 & 10.47 & 7.35 & 0.56 \\
MCBCTHI & 106.69 & 1.05 & 0.88 & 0.31 \\
MSVPWM & 134.88 & 2.14 & & 2.03 & \\
\hline
\end{tabular}

as input and Spartan 3E FPGA controllers to implement MSVPWM control is degined and presented.

\section{Conclusion}

This paper presents a modified ZSI integrated power conditioning system. To accomplish the desired AC output, cross conduction or shoot-through state control and Maximum Power Point Tracking in single power stage, four different control strategies are used and results are compared. Among them, modified SVPWM control technique maximizes voltage transfer ratio, reduces the voltage stress across the switches and minimizes the current ripple across the inductors in impedance network. Hence it is feasible to use modified SVPWM control strategy and can be applied to adjustable speed AC drives (ASDs). Moreover, modified ZSI topology reduces the capacitor voltage stress greatly. Hence reduction in size of capacitors in impedance network is achieved. Thus the cost of passive components required is less.

Using Matlab/Simulink environment, the simulation results are presented for the three-phase-voltage-type modified ZSI with solar PV as input to ascertain the effect 


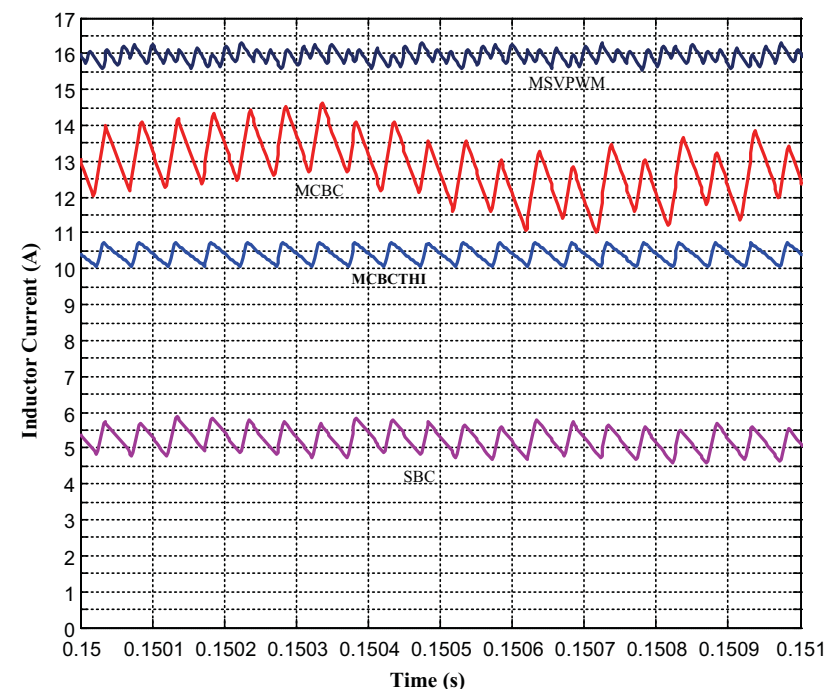

Figure 12. Inductor current ripple (steady state).
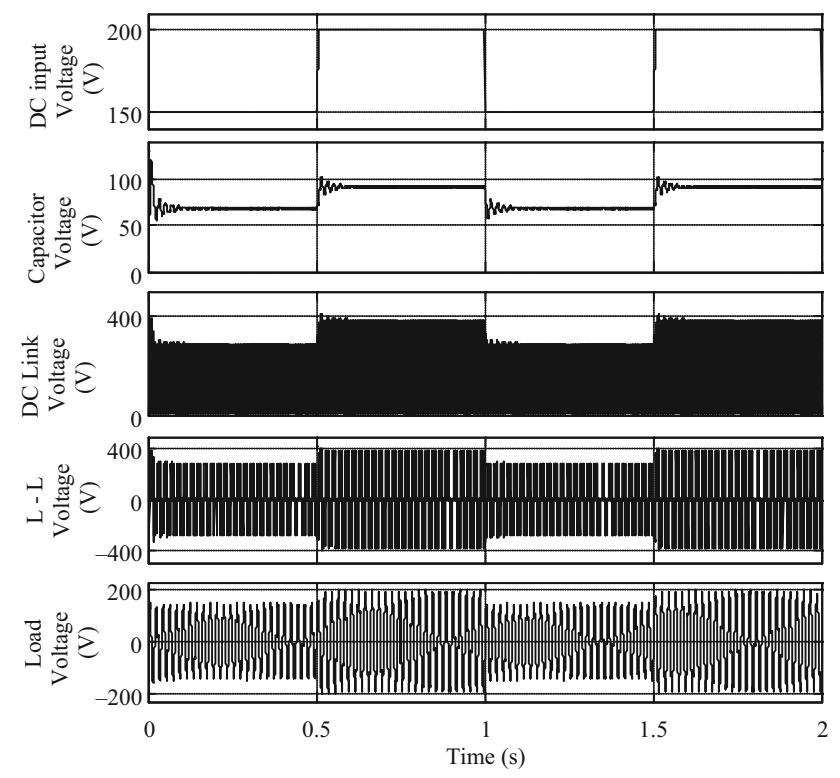

Figure 13. Effect of input DC voltage change.

of MSVPWM technique compared to other control techniques. Maximum power point has also been tracked simultaneously. It is also tested on the laboratory prototype modified ZSI with MSVPWM control using Spartan 3E FPGA controller for battery-powered applications. The proposed modified ZSI inherits all the advantages of classical ZSI and overcomes the drawbacks of classical ZSI. The aforementioned work has been implemented in open loop mode. Hence a change in input voltage will affect the capacitor voltage and inverter AC output. Therefore the

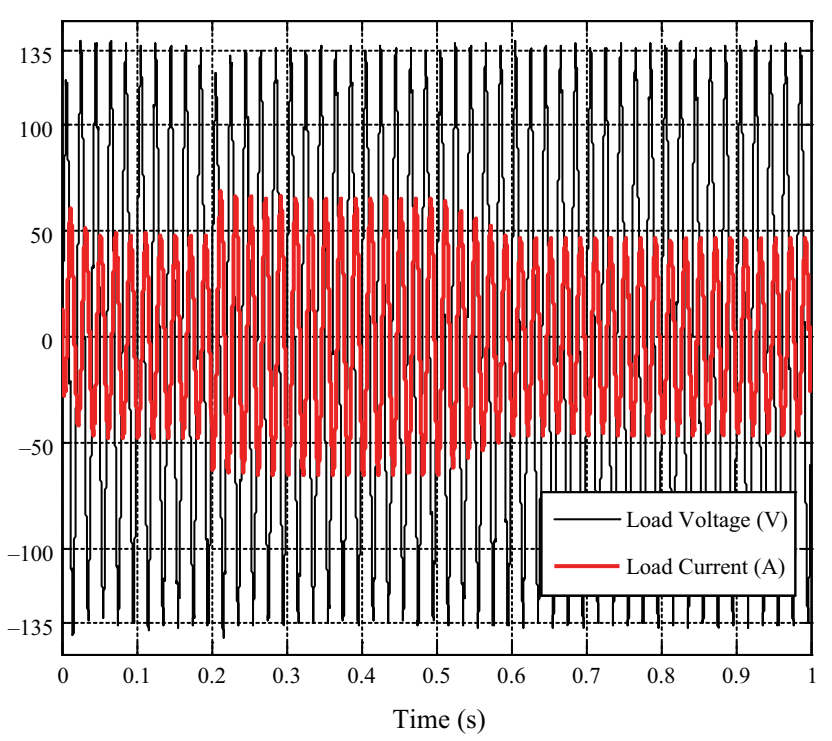

Figure 14. Effect of load current change.

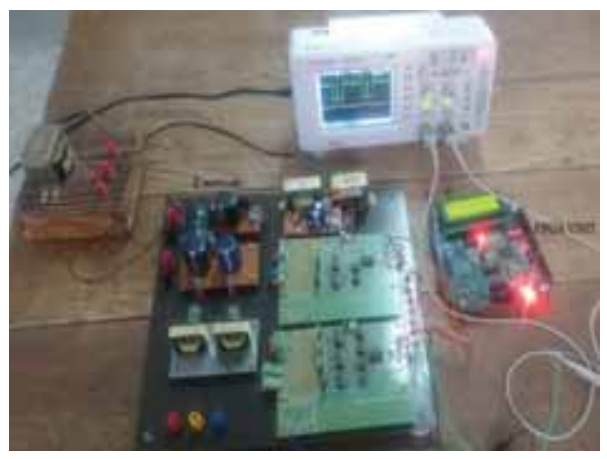

Figure 15. Experimental set-up.

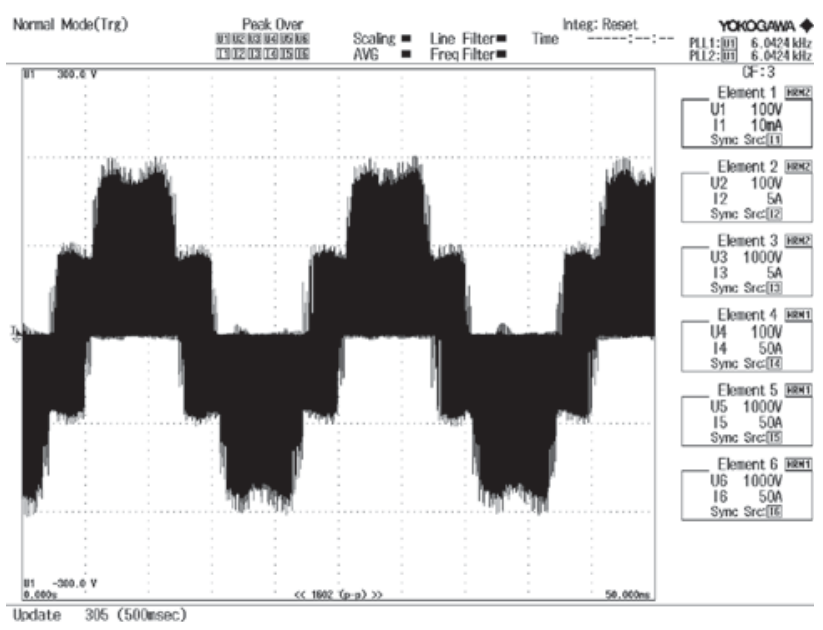

Figure 16. Inverter voltage/ph.

future work will be MSVPWM-controlled modified ZSI with suitable feedback and feed-forward controllers for ASDs. 


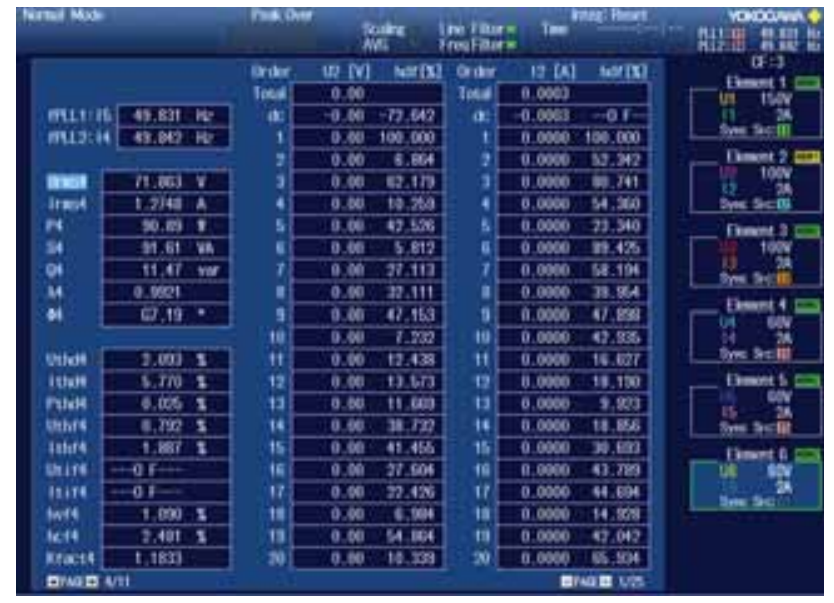

Figure 17. Detailed harmonic components.

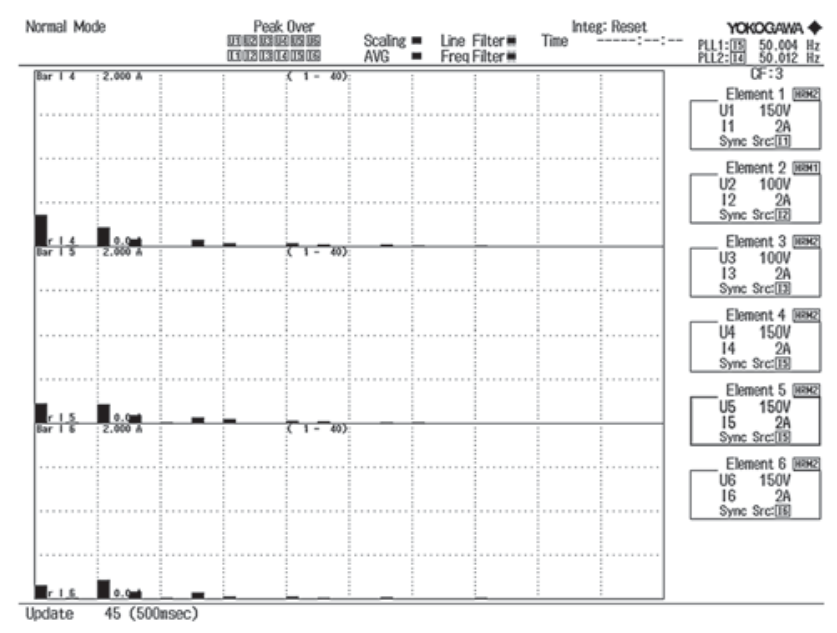

Figure 18. THD spectrum of inverter.

\section{List of symbols}

\section{$B$ boost factor}

$V_{C} \quad$ capacitor voltage

$V_{P N} \quad$ DC link voltage

$V_{P} \quad$ peak output voltage per phase

$D_{s h} \quad$ shoot-through duty ratio

$V_{d c} \quad$ input DC voltage

$M \quad$ modulation index

$G \quad$ voltage gain

$V_{S} \quad$ voltage stress

$T_{S} \quad$ time period for one switching cycle

$T_{\text {sh }} \quad$ shoot-through time period

$T_{1}, T_{2}$ time interval for active states

$T_{0} \quad$ time interval for null states

$P \quad$ power of $\mathrm{PV}$ panel

$V \quad$ voltage of PV panel

$I_{l} \quad$ average inductor current

$\Delta V_{c} \quad$ capacitor voltage ripple at peak power

$\Delta I_{l} \quad$ inductor current ripple at peak power

$f_{s} \quad$ switching frequency

\section{References}

[1] Huang Y, Shen M, Peng F Z and Wang J 2006 Z-source inverter for residential photovoltaic systems. IEEE Trans. Power Electron. 21(6): 1776-1782

[2] Peng F Z 2003 Z-source inverter. IEEE Trans. Ind. Appl. 39(2): 504-510

[3] Hosseinnia H, Nazarpour D and Sabernia S 2013 Simple boost control method optimized with genetic algorithm for Z-source inverter. J. Electr. Power Energy Convers. Syst. 1(1): $32-36$

[4] Ellabban O, Mierlo J V and Lataire P 2011 Experimental study of the shoot-through boost control methods for the Z-source inverter. EPE J. 21(2): 18-29

[5] Husodo B Y, Md. Ayob S, Anwari M and Taufik 2013 Simulations of modified simple boost control for Z-source inverter. Int. J. Autom. Power Eng. 2(4): 57-64

[6] Peng F Z, Shen M and Qian Z 2005 Maximum boost control of the Z-source inverter. IEEE Trans. Power Electron. 20(4): 833-838

[7] Shen M, Wang J, Joseph A, Peng F Z, Tolbert L M and Adams D J 2006 Constant boost control of the Z-source inverter to minimize current ripple and voltage stress. IEEE Trans. Ind. Appl. 42(3): 770-778

[8] Tang Y, Xie S, Zhang C and Xu Z 2009 Improved Z-source inverter with reduced $Z$-source capacitor voltage stress and softstart capability. IEEE Trans. Power Electron. 24(2): 409-415

[9] Tang Y, Xie S and Zhang C 2011 An improved Z-source inverter. IEEE Trans. Power Electron. 26(12): 3865-3868

[10] Peng F Z, Yuan X, Fang X and Qian Z 2003 Z-source inverter for adjustable speed drives. IEEE Power Electron. Lett. 1(2): 33-35

[11] Ellabban O, Mierlo J V and Lataire P 2009 Comparison between different PWM control methods for different Z-source inverter topologies. In: Proceedings of the 13th European Conference on Power Electronics and Applications, EPE '09, pp. 1-11

[12] Shen M, Wang J, Joseph A, Peng F Z, Tolbert L M and Adams D J 2004 Maximum constant boost control of the Z-source inverter. In: Proceedings of the IEEE Conference on Industry Applications, pp. 142-147

[13] Loh P C, Vilathgamuwa M, Lai Y S, Chua G T and Li Y W 2005 Pulse-width modulation of Z-source inverter. IEEE Trans. Power Electron. 20(6): 1346-1355

[14] Holtz J 1992 Pulse-width modulation-a survey. IEEE Trans. Ind. Electron. 39(5): 410-419

[15] Holmes D G 1996 The significance of zero space vector placement for carrier-based PWM schemes. IEEE Trans. Ind. Appl. 32(5): 1122-1129

[16] Thangaprakash S and Krishnan A 2012 A new switching scheme for Z-source inverter to minimize ripples in the Z-source elements. Int. J. Autom. Comput. 9(2): 200-210

[17] Al-Khatat M K 2010 Analysis of Z-source inverter for space vector PWM fed 3-phase induction motor. Eng. Tech. J. 28(17): 5440-5449

[18] Neacsu D O 2001 Space vector modulation-an introduction. In: Proceedings of IECON'01: The 27th Annual Conference of the IEEE Industrial Electronics Society, pp. 1583-1592

[19] Liu J, Hu J and Xu L 2005 A modified space vector PWM for Z-source inverter - modeling and design. In: Proceedings of 
the IEEE Conference on Electrical Machines and Systems, ICEMS 2005, pp. 1242-1247

[20] Thangaprakash S 2012 Unified MPPT control strategy for Z-source inverter based photovoltaic power conversion systems. J. Power Electron. 12(1): 172-180

[21] Rajakaruna S and Jayawickrama L 2005 Designing impedance network of $\mathrm{Z}$-source inverters. In: Proceedings of the 7th International Conference on Power Engineering, IPEC 2005, vol. 2, pp. 962-967

[22] Rajakaruna S and Jayawickrama L 2010 Steady-state analysis and designing impedance network of Z-source inverters. IEEE Trans. Ind. Electron. 57(7): 2483-2490

[23] Shen M, Wang J, Joseph A, Peng F Z and Adams D J 2007 Comparison of traditional inverters and Z-source inverter for fuel cell vehicles. IEEE Trans. Power Electron. 22(4): 1453-1463

[24] Pham C T, Shen A, Dzung P Q, Anh N B and Phu N X 2012 A comparison of control methods for Z-source inverter. Energy Power Eng. 4(4): 187-195
[25] Rostami H and Khaburi D A 2009 Voltage gain comparison of different control methods of the Z-source inverter. In: Proceedings of the International Conference on Electrical and Electronics Engineering, ELECO 2009, pp. I-268-I-272

[26] Thangaprakash S and Krishnan A 2010 Comparative evaluation of modified pulse width modulation schemes of Z-source inverter for various applications and demands. Int. J. Eng. Sci. Technol. 2(1): 103-115

[27] Tang Y, Xie S and Ding J 2013 Pulse width modulation of $\mathrm{Z}$-source inverters with minimum inductor current ripple. IEEE Trans. Ind. Electron. 61(1): 98-106

[28] Siwakoti Y P, Peng F Z, Blaabjerg F, Loh P C Town G E and Yang S 2015 Impedance-source networks for electric power conversion part ii: review of control and modulation techniques. IEEE Trans. Power Electron. 30(4): 1887-1906

[29] Tang Y and Xie S 2014 System design of series Z-source inverter with feed forward and space vector pulse-width modulation control strategy. IET Power Electron. 7(3): 736-744 